\title{
ПОВЫШЕНИЕ ЭНЕРГОЭФФЕКТИВНОСТИ ЭКОНОМИКИ УКРАИНЫ - МИССИЯ И ОСНОВНОЙ ПРИОРИТЕТ РАЗВИТИЯ ЭНЕРГЕТИКИ
}

\author{
Басок Б.И., член-корреспондент НАН Украины, Базеев Е.Т., канд. техн. наук \\ Институт технической теплофизики НАН Украины, ул. Желябова, 2а, Киев, 03680, Украина
}

Представлено обговорювані науковою громадськістю, у вигляді стратегій i експертних висновків, можливі тренди розвитку української енергетики для підвищення енергоефективності економіки України. Підкреслено роль енергоефективності в структурі енергетичних балансів - як основного потенційного екологічно чистого енергоресурсу.
Представлены обсуждаемые научной общественностью, в виде стратегий и экспертных заключений, возможные тренды развития украинской энергетики для повышения энергоэффективности экономики Украины. Подчеркнута роль энергоэффективности в структуре энергетических балансов - как основного потенциального экологически чистого энергоресурса.
Presented are the possible trends of development of the Ukrainian energy industry for improving the energy efficiency of Ukraine's economy, discussed by scientific community in the form of strategies and expert opinions. The role of improving energy efficiency in the structure of energy balances is emphasized as the main potential ecologically clean energy resource.

Библ. 20, рис. 5.

Ключевые слова: энергоеффективность, энергосбережение, теплообеспечение, экономика, энергетическая стратегия, энергоемкость, энергетическая политика, энергетические директивы ЕС.

Снижение промышленного производства и, соответственно, уменьшение спроса на энергоресурсы и энергоносители в течении последних 25 лет создавали в Украине некоторую иллюзию успокоенности и уверенности в том, что в топливно-энергетическом комплексе (ТЭК) страны ситуация относительно благополучная. При этом основные фонды ТЭК уже находятся на пределе физического и морального износа. Иллюстрацией такого отношения являлись периодические попытки в течение 20 лет, начиная с 1996 года, разработать (в формате энергетических стратегий) прогноз научно-технического развития отраслей ТЭК.

Первая энергетическая программа Украины на период до 2010 года была принята в виде Закона Украины в 1996 году [1]. Последующие варианты стратегий 2006 года и 2013 года были одобрены распоряжениями Кабинета Министров Украины [2, 3].

Проект “Энергетическая стратегия Украины на период до 2035 года" (ЭС-35), подготовленный в 2014 году Национальным институтом стратегических исследований, и проект "Новая энергетическая стратегия на период до 2020 года: безопасность, энергоэффективность, конкуренция" (НЭС-20), подготовленный в 2015 году Центром Розумкова, до сих проходят только общественное обсуждение. Ни одна из принятых стратегий не достигла своих прогнозируемых индикативных целей и показателей.

Отметим, что энергетические стратегии разрабатывались в сложных выходных условиях неопределённости многих базовых факторов: перспектив развития страны; геополитической турбулентности; финансовых мировых кризисов; скачкообразных изменений мировых цен на нефть; повышения требований по улучшению экологии планеты; появления новых рисков и вызовов. В этих условиях трудно было ожидать достижения основных прогнозируемых индикативных це- лей стратегий на достаточно продолжительный период (20...25 лет). Возможно, этим обстоятельством была вызвана необходимость уделить внимание коротким (до 5 лет) более конкретным планам (программным заданиям) с мероприятиями, направленными на повышение энергоэффективности производств как в секторах ТЭК так в других секторах экономики, что и отражено в проекте (НЭС-20) и в проекте "Середньострокового плану пріоритетних дій Уряду до 2020 року”, включающим раздел "підвищення енергетичної незалежності" [4]. Заметим, что в последнее время в Украине были приняты и запущены в реализацию два национальных плана - Национальный план действий по возобновляемой энергетике до 2020 г. и Национальный план повышения энергоэффекттивности до 2020 г.

В упомянутых выше документах термины и словосочетания энергоэффективность, энергосбережение, экономное, рациональное использование энергии зачастую отождествляются и трактуются, как само собою разумеющееся, что речь идёт об одном и том же, а именно: экономии энергии. Но энергоэффективность и энергосбережение - это разные по смыслу понятия.

Энергоэффективность - характеристика, отражающая отношение какого либо полезного эффекта (производство материальных ценностей, оказание услуг, проведение разного вида работ с использованием энергоресурсов) к затратам энергетических ресурсов в целях получения такого эффекта (И.А. Башмаков, Центр знергетической эффективности (ЦЭНЭФ-ХХІ, г. Москва), [5]). Энергоэффективность характеризует эффект от использования единицы энергии и измеряется в относительных единицах (положительный эффект/Дж) и имеет идеальным результатом, например, для теплоснабжения - это полное без потерь использование первичной энергии на создание надлежащего теплового режима комфорта в зонах пребывания человека. Энергоэффек- 
тивность, как правило, показатель, обратно пропорциональный энергоемкости производства продукта.

Энергосбережение - это реализация организационных, правовых, технических, технологических, экономических и иных мер, направленных на уменьшение объема используемых энергетических ресурсов при сохранении соответствующего полезного эффекта от их использования (в том числе объема произведенной продукции, выполненных работ, оказанных услуг) [6]. Важно подчеркнуть: "существующего полезного эффекта", иначе простое прекращение подачи теплоносителя для отопления или электроэнергии вплоть до отключения можно отнести к мероприятию "энергосбережение". Энергосбережение измеряется в абсолютных единицах (т у. т., Гкал, Дж и др.). В ныне действующем и достаточно устаревшем законе Украины об энергосбережении [7] приведена несколько иная трактовка термина «энергосбережение», а именно: "енергозбереження" - діяльність (організаційна, наукова, практична, інформаційна), яка спрямована на раціональне використання та економне витрачання первинної та перетвореної енергії і природних енергетичних ресурсів в національному господарстві і яка реалізується з використанням технічних, економічних та правових методів.

Дефицит энергии, случающийся на временных горизонтах (в периоды повышенных темпов экономического роста), покрывается в значительной степени вовлечением в энергетический баланс такого скрытого резерва как повышение энергоэффективности. В развитых странах энергоэффективность обеспечивала $60 \ldots 65 \%$ их экономического роста. В результате энер-

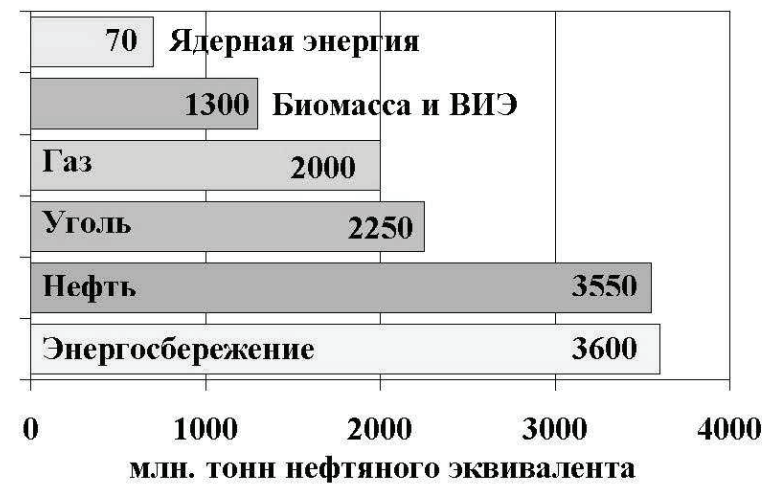

Рис. 1. Состав энергоресурсов в мировом балансе [11].

К началу XXI века энергоэффективность стала одним из основных энергоресурсов в энергетическом балансе мира (рис. 1) и Европейского сообщества (рис. 2). В энергобаланс Украины этот энергоресурс пока ещё не включён в должной мере (рис. 3). В литературе [12] появился уже термин, характеризующий повышение энергоэффективности - «негаджоуль»: nego - отрицаю (латин.), т.е. это как бы “виртуальные” джоули. Поскольку «негаджоули», вовлечённые в энергобаланс, не добываются из месторождений, не извлекаются из окружающей среды и они, естественно, не претерпевают никаких преобразований, то этот энергоресурс может быть отне- гоёмкость национального дохода снижалась в среднем в мире на $18 \%$, в развитых странах - на $21 \ldots 22 \%$. Эффективность инвестиций в энергоэффективность выше в 10..15 раз, чем эффективность вложений в поддержание и в увеличение энгергоресурсов и энергоносителей [8].

В современной мировой энергетике просматриваются новые тенденции, определяющие возрастание к середине XXI века роли трёх факторов: энергоэффективности, нетрадиционных источников энергии (в т. ч. возобновляемых и экологически чистых) и связанной с ними распределённой генерации, так называемыми интеллектуальными сетями передачи электроэнергии [9]. Энергетические эксперты начали оперировать современными понятиями: «новая энергетика», «чистая энергетика», «новая энергия», «интеллектуальная энергия», «цифровая энергия», биллинг, smart-системы, gridтехнологии, аддитивные технологии, «облачные» технологии, технологии big data. Кроме новых дефиниций появились и новые требования к классическим процессам энергогенерации, например, высокоэффективная когенерация (которая обеспечивает первичную экономию энергии по меньшей мере в $10 \%$ по сравнению с раздельным производством тепла и электроэнергии или маломасштабная и микрокогенерация); "эффективное централизованное теплоснабжение и охлаждение" (означает центральное теплоснабжение или охлаждение с помощью, по меньшей мере, 50 \% возобновляемых источников энергии, 50 \% отработанного тепла, 75 \% тепла от когенерации или 50 \% от комбинации указанных энергии и тепла) [10].

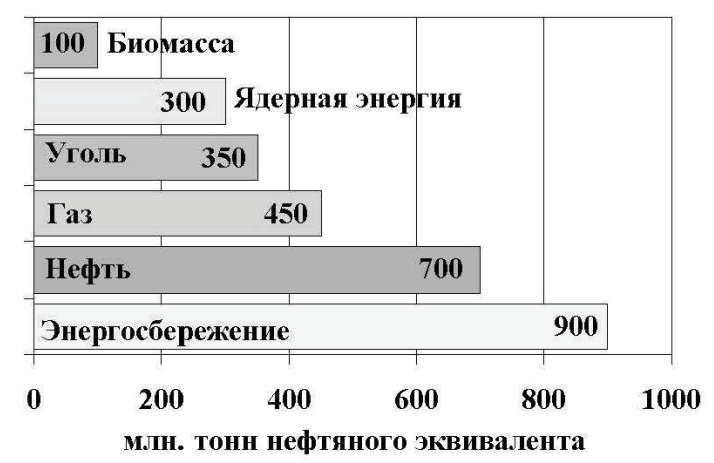

\section{Рис. 2. Энергосбережжение («негаджсули») - один из основных энергоресурсов в балансе ЕС [12].}

сён к экологически абсолютно чистым энергоресурсам.

Как видно из рис. 1 и 2, энергоресурсы в виде «негаджоулей» могут быть соизмеримы с другими энергоресурсами в структурном энергобалансе мира и Европы и, в частности, могут быть равны (рис. 1) или даже превышать (рис. 2) объёмы использования нефти.

Обострившаяся ситуация в украинской энергетике, в частности, импортозависимость от поставок газа и нефтепродуктов, недопоставки антрацита, отсутствие полноценных рыночных отношений в энергетике и др. негативные явления, углубила проблему диверсификации энергоресурсов. Основные пути решения находят- 
ся в вовлечении в энергобаланс других традиционных энергоресурсов, в то время как всё еще остаётся малозаметным и проигнорированным такой энергоресурс как негаджоули. Опыт работы по повышению энергоэффективности недостаточно систематизируется и пропагандируется, нет банка предлагаемых инновационных технологий и их иерархического ряда для выбора наиболее оптимальных. Игнорирование повышения энергоэффективности - это снижение экономического роста, угроза энергетической безопасности, снижение конкурентоспособности промышленности и инвестиционной привлекательности, повышения уровня бедности, повышение уровня загрязнения окружающей среды

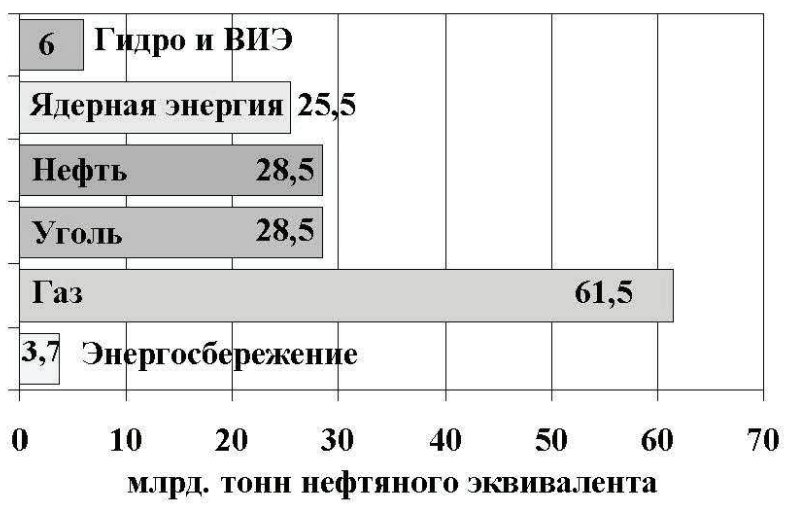

\section{Рис. 3. Структурный баланс энергоресурсов в Украине [13, 14].}

По данным ЦЭНЭФ-XXI в 1973-2011 годах за счёт повышения энергоэффективности было обеспечено более половины прироста потребности человечества в энергии. В эти годы мировой ВВП вырос в 3,3 раза, а потребление первичной энергии в 2,1 раза. Если бы энергоёмкость ВВП оставалась бы на постоянном уровне 1973 года, то прирост потребления энергии составил бы 14,1 млрд. т н.э., а фактически он составил 7 млрд. т н.э. Следовательно, вследствие повышения энергоэффективности было обеспечено половину прироста 7 млрд. т н.э. (рис. 5). В эти же годы приросты топлива и энергии составили (млрд. т н.): нефть - 135; уголь 2,28 ; природный газ - 1,81; ядерное топливо - 0,62 [5].

Для адекватного и полного представления стратегических направлений эволюции энергетики Украины важно располагать стратегией социально-экономического развития всей страны с учетом мировых тенденций развития экономических процессов. Документами последнего времени в этой сфере есть «Стратегия устойчивого развития «Украина - 2020» [16] и программа «Форсайт» [17].

C помощью методологии сценарного планирования и swot-анализа 50 экспертов провели уточнение восьми сценариев социально-экономического развития Украины вплоть до 2030 года [17]. С использованием дельфи- и SWOT-методов анализа проведено новое ши- и карбонизации экономики.

Совсем иное отношение к этому энергоресурсу в мире. Роль повышения энергоэффективности ярко видна при анализе динамики прироста ВВП и потребления первичных энергоресурсов (рис. 4). Например, в Германии практически отсутствует зависимость темпа экономического роста от производства энергоресурсов (больше того, имеется тенденция к снижению потребления энергоресурсов на 5 \%), в то время как в Украине за период с 2000 года по 2007 год темпы роста объёма ВВП и общего производства первичных топливно-энергетических ресурсов составили соответственно $164 \%$ и $127 \%$.

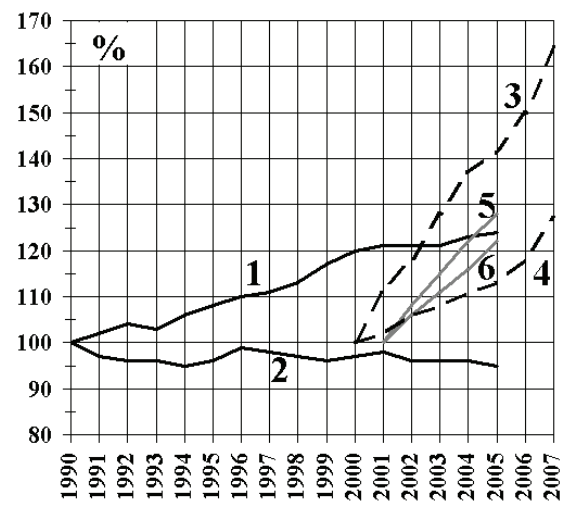

Рис. 4. Темпы экономического роста ВВП

(1, 3, 5 линии) и потребления первичной энергии (2, 4, 6 линии) Германии [15] (1, 2 линии), Украины [14] $(3,4)$ и России [15] $(5,6)$.

рокомасштабное экспертное исследование социальноэкономического сегмента общества, выполнена оценка наличия человеческого капитала в стране, способного осуществить прогрессивные преобразования, и выстроено пятьдесят главных действий власти в форме стратегии социально-экономического развития в среднесрочной и долгосрочной перспективе. Из восьми сценариев [17] желательными для Украины стали сценарий 1 («оптимистичный» до 2020 года) и сценарий 5 («сбалансированное развитие» до 2030 года).

Главную цель социально-экономического развития Украины на ближайшие 10 лет сформулировано следующим образом: «к 2025 году удвоить ВВП страны и довести его до 400...500 млрд. долл. США, сохраняя стабильность своих общественных и культурных систем и обеспечивая жизнеспособность собственной биосферы и ее способность самовозобновляться» [17].

Одним из девяти главных драйверов (кластеров), которые могут обеспечить успешную интеграцию страны в международную кооперацию труда на указанных временных горизонтах, является драйвер «новая энергетика». Ожидаемый вклад этого драйвера в ВВП страны оценивается в 5 \% к 2020 году и в 8 \% до 2025 года.

Представлены топ-5 критических факторов, тормозящих развитие экономики на временных горизонтах до 2020 и 2030 года. Среди указанных факторов важным 
является энергоемкость ВВП Украины (кг н.э./долл. США). Она должна быть снижена с 0,328 (2016) до 0,28 (2020) и 0,18 (2030). Вышеуказанная высокая энергоемкость ВВП является слабым фактором (индикатором). Количественное значение этого фактора по шкале Миллера (1-7) составляет 6 (2020) и 4,5 (2030) соответ-

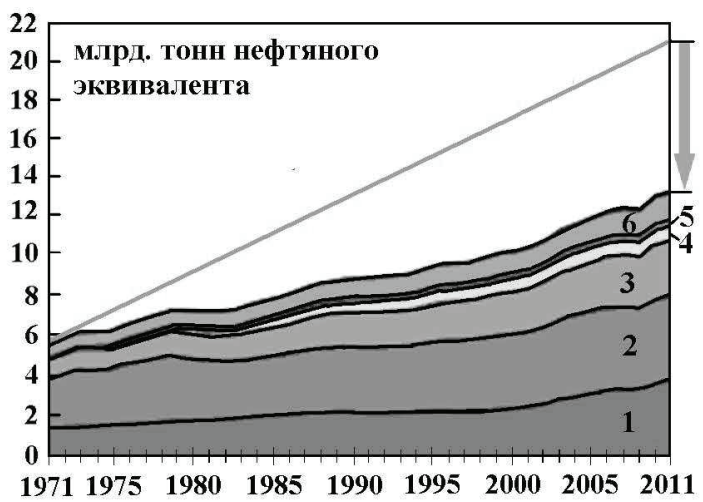

Рис. 5. Структурный мировой энергобаланс, данные МЭА, приведенные в [5]. Обозначения: 1 - уголь, 2 -нефть, 3 - природный газ; 4 -атомная энергия; 5 -гидроэнергия; 6 - биотопливо и отходы, стрелка-энергосбережение.

ственно. К слабым факторам, связанных с энергетикой, относятся также: импортозависимость, высокий уровень загрязнения атмосферного воздуха, нерациональное обращение с отходами, выбросами и сбросами, значительная карбоновая интенсивность экономики.

Согласно основной вышеуказанной цели, действия власти и общества должны быть направлены на: минимизацию топ-5 тормозящих факторов, в частности, «энергоемкости ВВП»; активизацию главных драйверов экономики Украины; подготовку в необходимых объемах и с необходимыми компетенциями человеческого капитала, способного к реализации вышеупомянутых преобразований.

Что касается минимизации «энергоемкости ВВП», то ее уменьшение должно быть в 3...5 раз, с переходом экономики Украины на «интеллектуальные» технологии, как менее энергоемкие, более высокорентабельные, экологически чистые.

Последовательность действий власти, направленных на активизацию главных кластеров экономики Украины, связанных, в частности, с энергетикой:

- внесение принципиальных изменений в энергетической политике Украины;

- широкое внедрение возобновляемой и альтернативной энергетики;

- законодательное закрепление особого характера возобновляемых источников энергии;

- разработка и внедрение программы модернизации энергетической отрасли;

- полномасштабное введение оптового рынка электроэнергии, газа, угля и тепловой энергии.

Определены сильные факторы и 10 драйверов по ускоренному развитию экономики Украины [17]. Относительно энергетики к сильным факторам можно отнести наличие сырьевой и ресурсной базы для атомной, возобновляемой энергетики и точного приборостроения, образованного трудоспособного корпуса специалистов-энергетиков.

Итак, одним из главных тормозящих факторов для развития экономики страны является высокая энергоемкость ВВП. Для снижения энергоемкости есть только один безальтернативный путь - повысить энергоэффективность секторов топливно-энергетического комплекса и всех отраслей экономики. Поэтому в Европе и в мире уже давно пришли к выводу, что энергоэффективность это главное направление при потреблении энергоресурсов и энергоносителей. Одновременно энергоэффективность - это главный потенциальный, экологически чистый энергоресурс.

Подводя промежуточный итог, следуют подчеркнуть современные устойчивые тенденции развития мировой энергетики:

- глобальное использование энергоэффективности и энергосбережения;

- устойчивое развитие общества, включая использование возобновляемой и альтернативной энергетики и повышение ее декарбонизации;

- информатизация и интеллектуализация энергетики [18, 19].

- смещение акцентов внимания с энергогенерации на эффективное распределение и, особенно, на конечного потребителя энергоресурсов - населения и экономику страны (мира). Переход от «рынка продавца» к «рынку покупателя». Изменение статуса потребителя, возможность конечного пользователя управлять энергосистемой.

На сегодня в ведущих странах формируется новая энергетическая философия, основные черты которой: энергоэффективность; интеллектуальные энергетические системы, построенные согласно концепции Smart Grid; децентрализация энергетики; новые источники энергии. Более того, в некоторых странах начался переход к энергетике 4-го инвестиционного цикла, а именно от модели «Энергоэффективность +» (ренессанс существующей энергетики (атомная, угольная, ВИЭ) при демпфировании ее негативных сторон; запуск программ энергоэффективности второй волны (on-line управления потреблением), CCS, усиление в балансе возобновляемой энергетики и т.д.) к концепции модели «Рынок мощности» (либерализация рынка в сфере генерации, рассредоточенная генерация; Smart Grid в версии «активные сети», вместо рынка энергетических услуг и топлива - рынок энергетических мощностей и выход на него «покупателя - продавца» (активные дома, электротранспорт и т.п.); перестройка городов) [20].

Ниже представлены ретроспективный взгляд по разработке политики повышения энергоэффективности при потреблении энергоресурсов. Снижение потребления энергии и устранения потерь энергии приобретает все большее значение для мира и, в частности для ЕС. В 2007 году лидеры ЕС решили снизить целевой пока- 
затель годового потребления энергии Европейского Союза для 2020 году на 20 \%. Мероприятия по повышению энергоэффективности все чаще проявляются в качестве средства не только достижения устойчивого энергоснабжения, сокращения выбросов парниковых газов, повышения безопасности поставок и снижения затрат на импорт, но и содействия конкурентоспособности европейских экономик. Европейский Совет 21 марта 2014 подтвердил действенность энергоэффективности по снижению затрат на энергию и уровня энергетической зависимости. Этому предшествовала последовательная политика ЕC по установлению стандартов энергоэффективности, в частности, были приняты основные «энергетические» директивы: 2006/32/ЕС об эффективности конечного использования энергии; 2012/27/ЕС об энергетической эффективности; 2004/8/EC о поощрении когенерации; 2009/28/ЕС о стимулировании использования энергии из возобновляемых источников; 2010/31/EC об энергетической эффективности зданий; 2003/87/EC, о торговле квотами на выброс парниковых газов; 2009/72/ЕС об общих правилах для внутреннего рынка электричества; 2009/73/ЕС об общих правилах для внутреннего рынка природного газа; 2009/31/EC о геологическом хранении углекислого газа; 2010/75/EC о промышленных выбросах; 2009/125/ЕС о введении правового регулирования для установления требований экодизайна к энергопотребляемой продукции; 2008/1/EC о комплексном предупреждении загрязнения и контроле над ним и некоторые другие: 2004/18/EC, 2009/125/EC, 2011/65/EC, 2012/19/ЕС а также стандарты современного энергетического менеджмента ISO 500XX.

Развитие тренда энергоэффективности в энергетической политике Украины.

В последнее время в Украине в законодательном поле и в политике исполнительной власти существенно интенсифицировалась деятельность по пропаганде энергоэффективности и реальным путям ее реализации в сфере энергетики. К знаковым мероприятиям в этом направлении относятся:

1. Разработка проекта новой энергетической стратегии Украины до 2035 года и его обсуждение в обществе. Следует заметить, что по сравнению со стратегиями 2006 и 2013 гг. в последнем проекте отдельными существенными блоками представлены: теплообеспечение населения и промышленности, возобновляемая энергетика и энергоэффективность, включая подраздел повышения энергоэффективности зданий. Причем в материалах стратегии до 2035 года, в которых рассматриваются конкретные сектора энергетики, на первое место ставится энергоэффективность, далее следуют электроэнергетика, теплоэнергетика, добыча газа, угля, нефти, а затем возобновляемая энергетика. Так расставлены приоритеты влияния на ситуацию в энергетике.

2. Реализация двух национальных планов действий до 2020 года - по возобновляемой энергетике и по энергоэффективности с соответствующими секторальными дорожными картами.

3. Разработка проектов нескольких энергозначимых законов Украины: по энергоэффективности зданий; по фонду энергоэффективности; по энергоэффективности; по коммерческому учету коммунальных услуг; по жилищно-коммунальным услугам; по тарифу на негазовую теплогенерацию; по созданию конкурентного рынка тепловой энергии; по энерго-сервисным компаниям (по состоянию на 1 апреля 2017 г.).

4. Проекты научно-технической и экспертной среды по прогнозированию на дальнюю перспективу социально-экономического развития Украины, включая подробные исследования совместной динамики экономики и энергетики.

Наибольший потенциал повышения энергоэффективности находится в сфере теплоснабжения жилищнокомунального хозяйства (ЖКХ) страны. Главной целью для коммунальной теплоэнергетики Украины становится выбор стратегически выверенных решений по развитию этой сферы ЖКХ - разработка руководящих документов государственного значения (концепции, стратегии, программы) и формирование на их основе научно-технической политики, создание комплекса нормативно-правовых актов и научно-организационных мероприятий, реализация которых обеспечит энергоэффективное использование энергоресурсов, энергетическую безопасность, устойчивое развитие и эффективное функционирование систем теплообеспечения населённых пунктов Украины.

\section{Выводы}

Развитию экономики и в т.ч. энергетики Украины в направлении повышения энергоэффективности и взвешенного использования возобновляемых энергоресурсов нет альтернативы. При этом трудно переоценить роль составляющей энергоэффективности в структуре энергетических балансов - как основного потенциального экологически чистого энергоресурса. Использование энергетического законодательства ЕС и его имплементация в экономику страны, безусловно адаптированного к национальным особенностям, в частности, необходимости установления компромисса между финансово-промышленными группами (занимающимися генерацией энергии), а также между ними и конечным потребителем энергии, дает шанс уменьшить удельную энергоемкость ВВП, повысить энергетическую независимость и усилить национальную безопасность, так необходимую Украине сегодня и в ближайшее время.

\section{ЛИТЕРАТУРА}

1. Постанова Верховної Ради Украӥни «Про Національну енергетичну програму України до 2010 року», 15 травня 1996 року, №191/96-ВР.

2. Про схвалення Енергетичної стратегії України на період до 2030 року. Розпорядження Кабінету Міністрів України від 15.03.2006, № 145-р.

3. Оновлена Енергетична стратегія України на період до 2030 року. Розпорядження КМ України від 2704 2013, №1070-р. "Про схвалення Енергетичної стратегії України на період до 2030 року".

4. http://www.kmu. gov. ua/control/publish/article? art id $=249634799$.

5. Башмаков И. Повышение энергоэффективности 
- главный энергетический ресурс (презентация). https:// www/cenef/ru/file/Stady.ppt .

6. Закон Российской Федерации от 23 ноября 2009 г. №261-Ф3 "Об энергосбережении и о повышении энергетической эффективности и о внесении изменений в отдельные законодательные акты Российской Федерации".

7. Закон Украӥни «Про енергозбереження». Постанова ВР №75/94-ВР від 01.07.1994.

8. Башмаков И. Месть проигнорированного приоритета «Энергетической стратегии России». // https:// www/cenef/ru/file/Bpaper101.pdf.

9. Порфирьев Б.Н., Рогинко С.А. Энергетика на возобновляемых источниках: Перспективы в мире и России. //Вестник РАН, т. 86, №11. - 2016. - С. 963-971.

10. Директива ЕС 2012/27/ЕС от 25 октября 2012 г. об энергетической эффективности.

11. Башмаков И. Закон повышающейся энергоэффективности. Енергоінформ, №27 (158), 2002.

12. Сам собi пан. Вісник української мережі “Енергоефективні міста”, №3-4, 2005. с.17.

13. Карп И.Н., Сухин Е.И. Количественная оценка влияния энергосберегающих технологий на экономию природного газа в промышленности и энергетике // Экотехнологии и энергосбережение. 2007. - №4. С. 24-44.
14. Національна доповідь про стан та перспективи реалізації державної політики енергоефективності у 2008 році. НАЕР, Київ. 2009. - 95 с.

15. Закиров Д.Г. Значение национального проекта в повышении энерогоэфективности и экономики регионов страны //Энергосбережение. 2008. - №8. - С. 56-62.

16. Стратегія сталого розвитку "Україна - 2020". Указ Президента України від 12 січня 2015 року, №5/2015.

17. «Форсайт 2016» - сценарій соціальноекономічного розвитку України до 2020 і 2030 років: анотація / керівник проекту М. З. Згуровський // - Київ: НТУУ “КПІ імені Ігоря Сікорського”. Видавництво "Політехніка", 2016. - 20 с.

18. Программа "Интеллектуальная энергия Европы". Решение 1639/2006/ЕС Европейского парламента и Совета ЕС от 24 октября 2006 г.

19. Інтелектуальні електричні мережі: елементи та режими: За заг. ред. акад. НАН України О.В. Кириленка / Інститут електродинаміки НАН України. - К.: Ін-т електродинаміки НАН України, 2016. - 405 с.

20. Денисюк С.П. Світові тенденції модернізації енергетичної інфраструктури. Пріоритети для України. Презентація. Конф. «Енергетичний менеджмент: стан та перспективи розвитку - PEMS'16. http://pems.kpi.ua/. 


\section{INCREASE OF ENERGY EFFICIENCY OF UKRAINE'S ECONOMY - MISSION AND THE MAIN PRIORITY OF DEVELOPMENT OF NATIVE ENERGY}

\section{Basok B.I., Bazeev T.T.}

Institute of Engineering Thermophysics of the National Academy of Sciences of Ukraine,

2a, Zhelyabova str., Kyiv, 03680, Ukraine

Possible trends in the development of Ukrainian energy for improving the energy efficiency of Ukraine's economy were considered. The role of improving energy efficiency in the structure of energy balances is emphasized as the main potential ecologically clean energy resource. The necessity of implementing the EC energy legislation, adapted to national peculiarities, was stressed in the economy of the country.

References 20, figures 5.

Key words: energy efficiency, energy saving, heat supply, economy, energy strategy, energy intensity, energy policy, innovative equipment, EU energetic directives.

\section{LITERATURE}

1. The Resolution of the Verkhovna Rada of Ukraine "About the national energy program of Ukraine until 2010", May 15 in 1996, №191/96-VR.

2. The approval of the Energy Strategy of Ukraine till 2030. Cabinet of Ministers of Ukraine dated 15.03.2006, № 145-p.

3. The updated Energy Strategy of Ukraine till 2030. Resolution of the Cabinet of Ukraine from April 27, 2013, №1070-p. "On approval of the Energy Strategy of Ukraine till 2030".

4. http://www.kmu. gov. ua/control/publish/article? art $i d=249634799$.

5. Bashmakov I. Increase energy efficiency - Chief power machinery resource (presentation of). https: //www/ cenef/ru/file/Stady.ppt.

6. Law of the Russian Federation No. 261-FZ of November 23, 2009 "On Energy Saving and on Increasing Energy Efficiency and on Amending Certain Legislative
Acts of the Russian Federation."

7. Law of Ukraine "On energy saving". VR Decision №75 / 94-VR of 01.07.1994.

8. Bashmakov I. Revenge of the ignored priority of the "Energy Strategy of Russia". // https: //www/cenef/ru/file/ Bpaper101.pdf.

9. Porfiryev B.N., Roginko S.A. Energy on renewable sources: Prospects in the world and Russia.//Vestnik RAN, v. 86 , No. 11. - 2016. - P. 963-971.

10. EC Directive 2012/27 / EC of 25 October 2012 on energy efficiency.

11. Bashmakov I. The law of increasing energy efficiency. Energoinform, No. 27 (158), 2002.

12. Mr Himself. Bulletin of the Ukrainian network "Energy Efficient Cities", №3-4, 2005. p. 17.

13. Karp I.N., Suhin E.I. Quantitative assessment of the impact of energy saving technologies on the economy of natural gas in industry and energy. Ecotechnologies and energy saving. 2007. № 4. PP. 24-44.

14. Zakirov D. G. The Importance of the National Project in Enhancing the Energy Efficiency and the Economy of the Regions of the Country. Energy Saving. 2008. №8. P. 56-62.

15. National Report on the prospects for the implementation of state energy efficiency policy in 2008. NAER Kyiv. 2009. - 95 p.

16. Strategy for Sustainable Development "Ukraine 2020". Decree of the President of Ukraine on January 12, 2015, №5 / 2015

17. "Foresight 2016" - scenario of socio-economic development of Ukraine for 2020 and 2030: Abstract / Project Manager MZZgurovsky. Kyiv: "KPI named Igor Sikorsky." Publishing house "Polytechnic", 2016. 20 p.

18. Program "Intellectual Energy of Europe". Decision 1639/2006 / EC of the European Parliament and of the Council of 24 October 2006

19. Intelligent electricity networks: elements and modes: The Society. Ed. Acad. NAS of Ukraine OV Kirilenko. Institute of Electrodynamics of NAS of Ukraine. K .Institute of Electrodynamics of NAS of Ukraine, 2016. $405 \mathrm{p}$.

20. Denisyuk S.P. Global trends of modernization of energy infrastructure. Priorities for Ukraine. 